\title{
HUBUNGAN DUKUNGAN KELUARGA DENGAN PEMENUHAN KEBUTUHAN SPIRITUAL LANSIA DI DESA TANAK TEPONG UTARA WILAYAH KERJA PUSKESMAS SEDAU
}

\author{
Kurnia Hariani ${ }^{1}$, Ni Nyoman Santi Tri Ulandari ${ }^{2}$, Febriati Astuti ${ }^{3}$ \\ ${ }^{1)}$ Mahasiswa Sekolah Tinggi Ilmu Kesehatan (STIKES) Mataram \\ ${ }^{2,3)}$ Staf Pengajar Sekolah Tinggi Ilmu Kesehatan (STIKES) Mataram \\ harianikurnia@yahoo.co.id
}

\begin{abstract}
ABSTRAK
Penuaan adalah suatu proses alami yang tidak dapat dihindari, berjalan secara terus menerus dan berkesinambungan. Lanjut usia mengalami proses penuaan yang mempengaruhi fungsi fisik, mental, psikososial dan perkembangan spiritual. Semakin bertambahnya usia, spiritual seseorang semakin bertambah. Kebutuhan spiritualitas pada lansia dipengaruhi oleh faktor usia yang sudah mulai renta atau uzur dan kondisi tidak aktif karena pensiun atau tidak bekerja. Spiritual memiliki hubungan yang erat dengan proses perubahan dan perkembangan manusia. Salah satu upaya yang dilakukan untuk memenuhi kebutuhan spiritualitas lansia adalah dengan melibatkan keluarga sebagai orang terdekat, yang sangat berperan penting terhadap pembentukan sikap ataupun prilaku lansia dalam melakukan aktivitas beribadah.

Penelitian ini bertujuan untuk mengidentifikasi hubungan dukungan keluarga dengan pemenuhan kebutuhan spiritual lansia di Desa Tanak Tepong Utara Wilayah kerja Puskesmas Sedau. Desain penelitian ini yaitu deskripsi analitik korelasi dengan pendekatan "Cross Sectional". Teknik pengambilan sampel pada penelitian ini menggunakan purposive sampling dengan jumlah sampel 53 lansia. Pengumpulan data dilakukan pada tanggal 3-18 Desember 2018, dengan menggunakan lembar wawancara dukungan keluarga dan pemenuhan kebutuhan spiritual lansia. Analisa data menggunakan uji spearman rank dengan $\alpha=0,05$.

Hasil Uji statistik spearman rank menunjukkan bahwa ada hubungan dukungan keluarga dengan pemenuhan kebutuhan spiritual lansia di Desa Tanak Tepong Utara Wilayah kerja Puskesmas Sedau dengan nilai $p=0,000(p<\alpha)$.

Berdasarkan penelitian yang telah dilakukan diharapkan dapat memberikan informasi bagi masyarakat bahwa dengan adanya dukungan keluarga yang baik, dapat memfasilitasi lansia khususnya dalam hal pemenuhan kebutuhan spiritual lansia terkait hubungannya dengan diri sendiri dan hubungan dengan alam.
\end{abstract}

Kata kunci: Lansia, Dukungan keluarga, Spiritual lansia

\section{PENDAHULUAN}

Masa lanjut usia (lansia) merupakan masa paling akhir dari siklus kehidupan manusia. Lansia bukan suatu penyakit, namun merupakan tahap lanjut dari suatu proses kehidupan yang ditandai dengan penurunan kemampuan tubuh untuk beradaptasi dengan stres lingkungan (Efendi \& Makhfudli, 2009).

Populasi lanjut usia di Indonesia di proyeksikan antara tahun 1990-2025 akan naik 414\% suatu angka yang tertinggi diseluruh dunia (United States 
Bureau of the Cencus dalam Darmojo dan Martono, 2011). Di NTB jumlah lansia dari data 3 tahun terakhir yaitu tahun 2015, 2016 dan 2017 meningkat. Data lansia pada tahun 2017 yang berusia 60 tahun ke atas berjumlah 520.043 lansia (NTB dalam angka, 2017).

Proses penuaan akan berdampak pada berbagai aspek kehidupan, baik sosial, ekonomi maupun kesehatan. Pada lanjut usia (lansia), akan terjadi perubahan fisik/biologis, psikologis, sosial dan ekonomi, yang mengakibatkan penurunan kemampuan lansia dalam beraktivitas, sehingga akan berpengaruh pada kemandirian lansia (S.Tamher \& Noorkasiani, 2009).

Kebutuhan akan dukungan dan perhatian keluarga berlangsung sepanjang hidup sehingga jika lansia tidak mendapatkan dukungan mereka akan merasa rendah diri, perasaan tidak berdaya, dan hal yang paling mengancam adalah keinginan untuk bunuh diri. Dengan adanya Ikatan kekeluargaan yang kuat sangat membantu ketika lansia menghadapi masalah, karena keluarga adalah orang yang paling dekat dengan lansia.

Peran keluarga dalam perawatan lansia yaitu menjaga dan merawat kondisi fisik anggota keluarga agar lansia tetap dalam keadaan optimal atau produktif, mempertahankan dan meningkatkan status mental pada lansia, mengantisipasi adanya perubahan sosial dan ekonomi pada lansia, memotivasi dan memfasilitasi lansia untuk memenuhi kebutuhan spiritual dengan demikian dapat meningkatkan ketaqwaan lansia terhadap Tuhan Yang Maha Esa. (Mubarak, 2006).

Kebutuhan spiritualitas pada lansia dipengaruhi oleh faktor usia yang sudah mulai renta atau uzur dan kondisi tidak aktif karena pensiun atau tidak bekerja. Spiritual memiliki hubungan yang erat dengan proses perubahan dan perkembangan manusia. Semakin bertambahnya usia, spiritual seseorang semakin bertambah karena mereka akan merasakan kedekatan dengan Tuhan. Rasa tersisih, tidak dibutuhkan lagi, ketidakikhlasan menerima kenyataan baru seperti penyakit yang tak kunjung sembuh, merupakan sebagian kecil masalah psikologis yang di alami lansia bila kebutuhan spiritualnya tidak terpenuhi yang akan berpengaruh pada kondisi fisik lansia tersebut.

Masalah spiritual menurut North American Nursing Diagnosis Association dapat disebut dengan distress spiritual. Kebutuhan spiritual yang terpenuhi pada masa ini akan membuat lansia mampu merumuskan arti personal yang positif tentang tujuan keberadaannya di dunia, mengembangkan arti penderitaan dan meyakini suatu hikmah dari suatu kejadian/penderitaan, menjalin hubungan yang positif dan dinamis melalui keyakinan, rasa percaya diri dan cinta. Lansia juga akan mampu membina integritas diri dan merasa dirinya berharga, merasakan kehidupan yang terarah terlihat melalui harapan, serta mampu mengembangkan hubungan antar manusia yang positif (Hamid, 2009).

Salah satu upaya yang dilakukan untuk memenuhi kebutuhan spiritualitas lansia adalah dengan melibatkan keluarga sebagai orang terdekat yang akan mencurahkan segala perhatiannya bagi kesejahteraan lansia khususnya kesejahteraan spiritualitas lansia (Alvianti, 2008).

Pengaruh lingkungan terutama keluarga sangat berperan penting terhadap pembentukan sikap ataupun prilaku lansia dalam melakukan aktivitas beribadah (Tasbih, 2014).

Puskesmas Sedau memiliki 7 wilayah kerja, yaitu Desa Keru, Sedau, Selat, Peresak, Suranadi, Lebah 
sempage, dan Sesaot. Jumlah lansia terbanyak pada tahun 2018 terdapat di Desa Peresak yaitu

10.063 lansia (Narmada dalam angka, 2018). Peneliti melakukan studi pendahuluan di Desa Tanak Tepong Utara Desa Peresak. Mayoritas penduduk di Desa Tanak Tepong Utara adalah muslim, di dapatkan 3 dari 5 orang lansia mengatakan jarang di ingatkan untuk sholat dan pergi beribadah ke tempat ibadah oleh keluarganya, dan 4 dari 5 lansia tersebut mengaku ada konflik dengan orang lain (tetangga) bahkan keluarga sendiri.

Data ini menunjukkan bahwa lansia belum mendapatkan perhatian tidak hanya dari aspek spiritual dalam hubungan dengan Tuhan tetapi juga dari karakteristik spiritual lainnya. Disinilah peran keluarga dibutuhkan dengan memperhatikan aspek karakteristik spiritual lainnya yaitu aspek hubungan dengan diri sendiri, hubungan dengan orang lain dan hubungan dengan alam.

\section{METODE}

Desain penelitian yang digunakan adalah deskripsi analitik korelasi dengan pendekatan "Cross Sectional".

Penelitian ini bertujuan untuk mengidentifikasi hubungan dukungan keluarga dengan pemenuhan kebutuhan spiritual lansia di Desa Tanak Tepong Utara Wilayah kerja Puskesmas Sedau.

Populasi dalam penelitian ini adalah seluruh lansia yang tinggal dengan keluarganya di Desa Tanak Tepong Utara Wilayah Kerja Puskesmas Sedau pada tahun 2017 yaitu 72 Lansia. Teknik pengambilan sampel pada penelitian ini menggunakan jenis purposive sampling, yaitu sampel dipilih berdasarkan ciri atau kriteria yang sudah diketahui sebelumnya.

Jumlah sampel pada penelitian ini yaitu semua lansia di Desa Tanak
Tepong Utara yang memenuhi kritteria inklusi yaitu 53 lansia.

Instrument yang digunakan pada penelitian ini yaitu lembar wawancara dukungan keluarga dan pemenuhan kebutuhan spiritual lansia. Analisa data yang digunakan yaitu spearman ranks dengan nilai $\alpha 0,05$

\section{HASIL}

Tabel 1. Distribusi karakteristik responden

\begin{tabular}{|c|c|c|c|}
\hline No. & Variabel & $\begin{array}{c}\text { Frekuensi } \\
\text { (n) }\end{array}$ & $\begin{array}{c}\text { Presentase } \\
(\%)\end{array}$ \\
\hline 1. & $\begin{array}{c}\text { Umur (Tahun): } \\
60-74 \\
75-80\end{array}$ & $\begin{array}{l}39 \\
14\end{array}$ & $\begin{array}{l}73,8 \\
26,2\end{array}$ \\
\hline 2. & $\begin{array}{c}\text { Jenis kelamin: } \\
\text { laki-laki } \\
\text { Perempuan } \\
\end{array}$ & $\begin{array}{l}14 \\
39 \\
\end{array}$ & $\begin{array}{l}24,2 \\
73,8\end{array}$ \\
\hline 3. & $\begin{array}{c}\text { Pendidikan : } \\
\text { Tidak } \\
\text { sekolah } \\
\text { SD } \\
\text { SMP } \\
\text { SMA } \\
\end{array}$ & $\begin{array}{c}29 \\
21 \\
2 \\
1 \\
\end{array}$ & $\begin{array}{r}54,7 \\
39,6 \\
3,8 \\
1,9 \\
\end{array}$ \\
\hline 4. & $\begin{array}{l}\text { Status } \\
\text { pernikahan: } \\
\text { Menikah } \\
\text { Duda } \\
\text { Janda }\end{array}$ & $\begin{array}{c}33 \\
5 \\
15\end{array}$ & $\begin{array}{c}62,3 \\
9,4 \\
28,3\end{array}$ \\
\hline
\end{tabular}

Sumber : Data primer (2018)

Berdasarkan tabel 1 di atas dapat dilihat bahwa responden yang jumlahnya paling banyak yaitu "elderly"(60-74) tahun berjumlah 39 orang $(73,8 \%)$. Distribusi responden berdasarkan jenis kelamin yang terbanyak yaitu perempuan berjumlah $39(73,8 \%)$. Dan dari tingkat pendidikan responden terbanyak dengan tingkat pendidikan tidak sekolah yaitu berjumlah 29 responden dengan presentase 54,7\%, sedangkan untuk status pernikahan responden terbanyak yaitu yang menikah dengan presentase $62,3 \%$ berjumlah 33 responden. 
Tabel.2. Distribusi dukungan keluarga

\begin{tabular}{|l|l|l|l|}
\hline No. & $\begin{array}{c}\text { Dukungan } \\
\text { keluarga }\end{array}$ & $\begin{array}{c}\text { Frekuensi } \\
(\mathrm{n})\end{array}$ & $\begin{array}{c}\text { Presentase }(\% \\
)\end{array}$ \\
\hline 1. & Baik & 42 & 79,2 \\
\hline 2. & Cukup & 8 & 15,1 \\
\hline 3. & Kurang & 3 & 5,7 \\
\hline \multicolumn{2}{|l}{ Total } & 53 & 100 \\
\hline
\end{tabular}

Sumber : Data primer (2018)

Tabel 2. Menunjukkan bahwa sebagian besar responden memiliki dukungan dengan kategori baik berjumlah 42 responden $(79,2 \%)$.

Tabel.3. Distribusi subvariabel dukungan keluarga

\begin{tabular}{|l|l|l|}
\hline NO. & \multicolumn{1}{|c|}{ Dukungan keluarga } & $\begin{array}{c}\text { Persentase } \\
(\%)\end{array}$ \\
\hline 1. & Dukungan informasional & 73,0 \\
\hline 2. & Dukungan penilaian & 95 \\
\hline 3. & Dukungan instrumental & 89,9 \\
\hline 4. & Dukungan emosional & 76,7 \\
\hline
\end{tabular}

Sumber : Data primer (2018)

Tabel 3 menunjukkan presentase dukungan yang paling tinggi yaitu dukungan penilaian (95\%) dan yang paling rendah adalah dukungan infromasional (73\%).

Tabel 4. Distribusi pemenuhan kebutuhan spiritual

\begin{tabular}{|l|l|c|c|}
\hline No. & $\begin{array}{c}\text { Pemenuhan } \\
\text { kebutuhan } \\
\text { spiritual } \\
\text { lansia }\end{array}$ & $\begin{array}{c}\text { Frekuensi } \\
(\mathrm{n})\end{array}$ & $\begin{array}{c}\text { Presentase } \\
(\%)\end{array}$ \\
\hline 1. & Baik & 45 & 84,9 \\
\hline 2. & Cukup & 7 & 13,2 \\
\hline 3. & Kurang & 1 & 1,9 \\
\hline Total & & 53 & 100 \\
\hline
\end{tabular}

Sumber : Data primer (2018)

Tabel 4. Menunjukkan pemenuhan kebutuhan spiritual lansia sebagian besar dalam kategori baik dengan jumlah 45 $(84,9 \%)$ responden.

Tabel 5. Distribusi subvariabel pemenuhan kebutuhan spiritual

\begin{tabular}{|c|l|c|}
\hline NO. & $\begin{array}{c}\text { Pemenuhan kebutuhan } \\
\text { spiritual lansia }\end{array}$ & $\begin{array}{c}\text { Persentase } \\
(\%)\end{array}$ \\
\hline 1. & Hubungan dengan diri sendiri & 78 \\
\hline 2. & Hubungan dengan orang lain & 86 \\
\hline
\end{tabular}

\begin{tabular}{|c|l|l|}
\hline 3. & Hubungan dengan alam & 78 \\
\hline 4. & Hubungan dengan Tuhan & 85 \\
\hline
\end{tabular}

Sumber: Data primer (2018)

Tabel 5. Menunjukkan indicator pemenuhan kebutuhan spiritual yang tertinggi yaitu hubungan dengan orang lain $(86 \%)$ dan yang paling rendah yaitu hubungan dengan diri sendiri dan hubungan dengan alam (78\%).

Tabel 6. Tabulasi silang hubungan dukungan keluargadengan pemenuhan kebutuhan spiritual lansia.

\begin{tabular}{|c|c|c|c|c|c|c|c|c|c|}
\hline \multirow{3}{*}{ No. } & \multirow{3}{*}{$\begin{array}{c}\text { Dukungan } \\
\text { keluarga }\end{array}$} & \multicolumn{6}{|c|}{ Pemenuhan Kebutuhan spiritual } & \multicolumn{2}{|c|}{$\begin{array}{l}\text { Jumlah } \\
\text { total }\end{array}$} \\
\hline & & \multicolumn{2}{|c|}{ Baik } & \multicolumn{2}{|c|}{ Cukup } & \multicolumn{2}{|c|}{ Kurang } & & \\
\hline & & $\mathrm{N}$ & $\%$ & $\mathrm{~N}$ & $\%$ & $\mathrm{~N}$ & $\%$ & $\mathrm{~N}$ & $\%$ \\
\hline 1. & Baik & 39 & 92,9 & 3 & 7,1 & 0 & 0 & 42 & 100 \\
\hline 2. & Cukup & 6 & 75 & 2 & 25 & 0 & 0 & 8 & 100 \\
\hline 3. & $\begin{array}{l}\text { Kuran } \\
\text { g }\end{array}$ & 0 & 0 & 2 & 66,7 & 1 & 33,3 & 3 & 100 \\
\hline \multicolumn{2}{|c|}{ Total } & 45 & 84,9 & 7 & 13,2 & 1 & 1,9 & 53 & 100 \\
\hline
\end{tabular}

Tabel 6 menunjukkan bahwa responden dengan dukungan keluarga baik didapatkan yang memiliki pemenuhan kebutuhan spiritual baik berjumlah $39(92,9 \%)$ responden, yang memiliki dukungan keluarga cukup dengan pemenuhan kebutuhan spiritual yang cukup berjumlah 2 (25\%) responden danyang memiliki dukungan keluarga yang kurang dengan pemenuhan kebutuhan spiritual yang kurang berjumlah $1(1,9 \%)$ responden.

Hasil analisa data uji statistik Spearman rank test diperoleh nilai $p$ value adalah 0,000 . Dimana $(\alpha)<0,05$ sehingga dapat diambil kesimpulan Ho ditolak dan Ha diterima, berarti terdapat hubungan dukungan keluarga dengan pemenuhan kebutuhan spiritual lansia di Desa Tanak tepong Utara Wilayah kerja Puskesmas Sedau. Berdasarkan kekuatan hubungan nilai koefisien korelasi 0,484 masuk dalam kategori cukup.

\section{PEMBAHASAN}

Kelompok usia pertengahan dan lansia mempunyai lebih banyak waktu untuk kegiatan agama dan berusaha 
untuk mengerti nilai agama yang diyakini oleh generasi muda.

Syam (2010) mengatakan bertambahnya usia meningkatkan kematangan dalam berfikir dan bertindak sehingga segi spiritual lansia menjadi lebih baik yang akan berpengaruh dalam mengambil keputusan dan menentukan sikap dalam kehidupan sehari-hari.

Hamid (2009) menjelaskan bahwa tahap perkembangan manusia mempengaruhi status spiritual seseorang.

Meisenhelder (2003) melakukan analisis sekunder pada 271 orang berusia lebih dari 65 tahun untuk meneliti perbedaan jenis kelamin pada koping keagamaan, keimanan, dan frekuensi berdoa. Hasil analisis ini menunjukkan bahwa terdapat perbedaan antara lansia yang berjenis kelamin laki-laki dan perempuan pada spiritualitas mereka.

Frekuensi berdoa, sebuah indikator kebiasaan, terbukti berhubungan positif dengan kesehatan mental untuk responden yang berjenis kelamin lakilaki sedangkan keterikatan pada koping keagamaan dan pentingnya keimanan seseorang berhubungan positif dengan responden berjenis kelamin perempuan.Penelitian yang dilakukan oleh Perinotti-Molinatti (2004) yang menyatakan bahwa sejarah keluarga seseorang, pendidikan, dan latar belakang agama memainkan peran utama dalam kehidupan spiritualitas lansia.

Dukungan keluarga adalah semua bentuk prilaku dan sikap positif yang diberikan pada salah satu anggota keluarga dalam hal ini lansia, membutuhkan dukungan keluarga (Kartinah \& Kresnawati, 2011). Hamid (2009) mengatakan bahwa lansia yang kehilangan pasangan atau tidak dapat berkumpul dengan keluarga atau teman dekat akan terpisahkan dari ikatan spiritual sehingga menyebabkan perubahan fungsi spiritualnya, keyakinan spiritual yang terbangun dengan baik membantu lansia menghadapi kenyataan. Salah satu kenyataan yang dihadapi lansia adalah menerima kematian pasangan. Potter dan Perry (2010) menjelaskan bahwa salah satu tugas perkembangan lansia adalah beradaptasi terhadap kematian pasangan, sehingga lansia yang telah ditinggal oleh pasangan harus mampu menyesuaikan dengan keadaan.

Stanley, Blair dan Beare (2005) sumber pendukung pertama biasanya merupakan anggota keluarga seperti pasangan, anak-anak, saudara kandung atau cucu. Penelitian yang dilakukan Setiti (2007) menyebutkan bahwa lansia membutuhkan kebutuhan psikis diantaranya yaitu dukungan emosional dimana lansia butuh lingkungan yang mengerti dan memahami mereka. Lansia membutuhkan teman untuk bicara, sering dikunjungi, dan sering disapa.

Pada masa ini, manusia sudah tidak produktif lagi, kondisi fisik sudah menurun, sehingga berbagai penyakit siap menggerogoti mereka. Dengan demikian, pada usia ini muncul semacam pemikiran bahwa mereka berada pada sisa-sisa umur menunggu datangnya kematian. Sehingga cenderung mendekatkan diri pada Sang pencipta, dan berusaha memperbanyak amal ibadah, agar lebih siap menghadapi kematian (Stanley, 2006).

Spiritualitas bagi lansia menjadi sangat penting karena sebagai usaha mempersiapkan para lansia dalam menghadapi saat-saat akhir.

Kebutuhan spiritual adalah kebutuhan untuk mempertahankan atau mengembalikan keyakinan dan memenuhi kewajiban agama, serta kebutuhan untuk mendapatkan maaf atau pengampunan, mencintai, menjalin hubungan penuh rasa percaya dengan Tuhan, sehingga dapat disimpulkan 
kebutuhan spiritual merupakan kebutuhan untuk mencari arti dan tujuan hidup, kebutuhan untuk mencintai dan dicintai serta rasa keterikatan dan kebutuhan untuk memberikan dan mendapatkan maaf (Rio, 2011).

Kebutuhan spiritualitas tidak dapat dipisahkan dari berbagai faktor yang mempengaruhi, diantaranya adalah perkembangan, budaya, keluarga, agama, pengalaman hidup sebelumnya, krisis dan perubahan (Hamid, 2009). Upaya yang dilakukan untuk memenuhi kebutuhan spiritualitas lansia adalah dengan melibatkan keluarga sebagai orang terdekat akan mencurahkan segala perhatiannya bagi kesejahteraan lansia khususnya kesejahteraan spiritualitas lansia (Alvianti, 2008).

Dukungan keluarga dapat berupa dukungan internal, yaitu seperti dukungan dari suami atau istri atau dukungan dari saudara kandung dan dukungan eksternal, yaitu seperti dukungan dari keluarga besar atau dukungan sosial (Friedman et al., 2010). Dukungan yang dapat diberikan keluarga bagi lansia salah satunya adalah dukungan instrumental yang dapat berupa membantu kegiatan spiritual, menyediakan keperluan yang bersangkutan dengan kegiatan Ibadah.

Pada saat peneliti melakukan wawancara, lansia mengatakan sering di ingatkan oleh keluarga untuk melakukan ibadah sholat, dzikir baik dalam keadaan sehat maupun sakit, dan diperlakukan dengan baik oleh keluarganya, sering di ajak komunikasi dan di kunjungi. Sebagian besar lansia juga mengatakan menyempatkan diri untuk mengikuti pengajian yang dilakukan di masjid ataupun mushola di sekitar rumah walaupun tidak rutin.

Penelitian ini sejalan dengan penelitian yang dilakukan oleh Fitriyuningsih (2015) hasil penelitian menunjukkan bahwa peran keluarga dalam pemenuhan kebutuhan spiritual lansia dikategorikan baik karena banyak lansia yang tinggal bersama keluarga seperti anak kandungnya dan pasangannya. Keluarga dan teman dekat dapat memberikan bantuan dan dukungan emosional bagi lansia ketika menghadapi suatu masalah.

Hasil penelitian oleh Koenig, George, dan Siegler 1988, dalam (Hefner, 2008), agama dan spiritual adalah sumber koping yang biasanya digunakan oleh lansia ketika mengalami sedih, kesepian dan kehilangan. Hasil studi menunjukkan bahwa tingkat spiritualitas pada lansia setelah mencapai usia 70 tahun, maka lansia ada pada level di mana penyesalan dan tobat berperan dalam penebusan dosa-dosa.

Peranan keluarga dalam perawatan lansia antara lain menjaga dan merawat lansia, mempertahankan dan meningkatkan status mental,

mengantisipasi perubahan sosial ekonomi, serta memberikan motivasi dukungan dan memfasilitasi kebutuhan spiritual bagi lansia (Maryam, 2008).

\section{SIMPULAN DAN SARAN}

\section{Kesimpulan :}

1. Dukungan keluarga pada lansia di Desa Tanak Tepong Utara Wilayah kerja Puskesmas Sedau termasuk kategori baik

2. Pemenuhan kebutuhan spiritual lansia di Desa Tanak tepong Utara Wilayah kerja Puskesmas Sedau termasuk kategori baik

3. Ada hubungan dukungan keluarga dengan pemenuhan kebutuhan spiritual lansia di Desa Tanak Tepong Utara Wilayah kerja Puskesmas Sedau. karena nilainilai p-value adalah 0,000 . Dimana $(\alpha)<0,05$ yang artinya Ho ditolak dan $\mathrm{Ha}$ diterima. 


\section{Saran :}

Diharapkan hasil penelitian dapat memberikan informasi bagi masyarakat bahwa dengan adanya dukungan keluarga yang baik, diharapkan dapat memfasilitasi lansia khususnya dalam hal pemenuhan kebutuhan spiritual lansia terkait hubungannya dengan diri sendiri dan hubungan dengan alam.

\section{DAFTAR PUSTAKA}

Archiliandi. 2016. Jurnal Keperawatan. Gambaran Pemenuhan Kebutuhan Spiritual Care Oleh Perawat Kepada Pasien Rawat Inap RS PKU Muhammadiyah Bantul. Vol 5. Hal 5-12.

Arikunto, 2007. Prosedur Penelitian. Rineka Cipta: Jakarta

Badan Pusat Statistik Lombok Barat, 2018. Narmada Dalam Angka Tahun 2018.Badan Pusat Statistik: Lombok Barat

Badan Pusat Statistik, 2017. Nusa Tenggara Barat Dalam Angka.Badan Pusat Statistik: NTB

Chen LPN \& Sumari M, 2012. Malaysia women survivor perspective on healing from childhood sexual abuse through spirituality. International Congress on Interdisciplinary Business and Social Science 2012. Social and Behavioral Science: Procedia

Dwina, P. 2016. Hubungan pengabaian pada lansia dengan pemenuhan kebutuhan spiritual lansia Desa Blang Kecamatan Darussalam Aceh Besar. (Skripsi). Unsiyah. Aceh.

Fatimah, 2010. Merawat Manusia Lanjut Usia. Trans Info Media: Jakarta.

Friedman, M. M., 2013. Buku Ajar Keperawatan Keluarga: Riset, Teori dan Praktik. EGC: Jakarta.

Hamid AYS, 2009. Bunga Rampai Asuhan Keperawatan Kesehatan
Jiwa. EGC: Jakarta.

Harnilawati, 2013. Konsep dan Proses Keperawatan Keluarga. Pustaka As Salam: Sulawesi Selatan.

Kementerian Kesehatan Republik Indonesia, 2014. Profil Kesehatan Indonesia 2013.

Kementerian Kesehatan RI. Kharisma, F. 2018. Jurnal Keperawatan Indonesia. Hubungan pencapaian tugas perkembangan keluarga tahap VIII (aging Family) dengan prilaku pemenuhan kebutuhan spiritual: Sholat pada Lansia. Vol 7. Hal 310.

Kozier, B., Erb, Berman, \& Snyder. 2008. Buku Ajar Praktik Keperawatan Klinis Kozier Erb. EGC:

Jakarta.https://books.google.com di akses pada tanggal 30 Agustus 2018 pukul 18.00 wita

Maryam, R. Siti., Ekasari, Rosidawati, Jubaedi, A., Batubara, I. 2008. Mengenal Usia Lanjut dan Perawatannya. Salemba Medika: Jakarta 2010. Jurnal Keperawatan. Hubungan antara kesehatan spiritual dengan kesehatan jiwa pada lansia muslim di sasana tresna werdha KBRP Jakarta Timur. Vol 6. 9-16.

Notoatmodjo, 2010. Metodologi Penelitian Kesehatan. Rineka Cipta: Jakarta.

Nursalam, 2016. Metode Penelitian Ilmu Keperawatan Pendekatan Klinis. Salemba Medika: Jakarta.

Perinotti-Molinatti, Joseph. 2004. The Significance Of Spirituality In The Elderly. Boca Raton, Florida:

Potter, P. A \& Perry, A. G. 2010. Fundamentals of nursing edisi 7. Salemba Medika: Jakarta.

Purnawan. 2015.Jurnal Keperawatan. Pemenuhan Kebutuhan Spiritual: Shalat dan Thaharoh Pasien Stroke di Rumah Sakit Pusat Kesehatan Umum Muhammadiyah 
Gamping. Hal 3-20.

Santika. 2014. Jurnal Keperawatan.

Hubungan pencapaian tugas perkembangan keluarga Tahap VIII (aging family) dengan prilaku pemenuhan kebutuhan spiritual: Sholat pada Lansia. Vol 12. Hal 515.

Stanley, M., Beare, Patricia. 2012. Buku ajar keperawatan gerontik. Edisi 2. EGC: Jakarta.

STIKES MATARAM. 2018.

Buku Panduan Skripsi 2018/2019 Mataram.

Sudaryanto, A. 2013. Spiritualitas lanjut usia (lansia) di unit pelayanan teknis panti sosial lanjut usia magetan. (skripsi). Universitas Muhamadiyah Surakarta.

Surakarta

Sugiyono, 2015. Metode Penelitian Kuantitatif, Kualitatif dan $R \& D$. Alfabeta: Bandung.

Ummah, Athurrita. 2016. Jurnal Keperawatan. Hubungan kebutuhan spiritual Dengan Kualitas Hidup Pada Lansia di Panti Wredha Kota Semarang. Vol 4. 10-16.

Young, Koopsen. 2007. Spiritualitas, Kesehatan dan Penyembuhan. Bina Media perintis: Medan.

Yulianti. Pendekatan cultural spiritual dalam konseling bagi lansia. Bandung: UIN Sunan Gunung Djati, 2011.

Yuningsih, F. 2012. Jurnal keperawatan. Peran Keluarga Dalam MemenuhiSpiritual Lansia di Desa Buluh Duri di Desa Sipispis Kabupaten Serdang Bedagai. (skripsi). USU. Sumatera. 